\title{
Author Correction: Beta cell connectivity in pancreatic islets: a type 2 diabetes target?
}

\author{
Guy A. Rutter ${ }^{1}$. David J. Hodson ${ }^{1}$
}

Published online: 15 February 2018

๑) Springer International Publishing AG, part of Springer Nature 2018

\section{Author Correction to: Cell. Mol. Life Sci. (2015) 72:453-467 https://doi.org/10.1007/ s00018-014-1755-4}

The original version of this article unfortunately contained a mistake. Legends of Figs. 1 and 2 were interchanged. The correct versions are given below. s00018-014-1755-4.

Guy A. Rutter g.rutter@imperial.ac.uk

David J. Hodson

d.hodson@imperial.ac.uk

1 Section of Cell Biology, Department of Medicine, Imperial College London, Imperial Centre for Translational and Experimental Medicine, Hammersmith Hospital, Du Cane Road, London W12 0NN, UK 
Fig. 1 Imaging and mapping beta cell network topology. (Above) Functional multicellular $\mathrm{Ca}^{2+}$ imaging is used to monitor the large-scale organization of glucose-induced population dynamics (above, left). By subjecting the resulting traces (from 50-100 individual cells per islet) to correlation analyses, cells with coordinated activity can be identified and a functional connectivity map plotted based upon position within the imaged field $(\mathrm{x}-\mathrm{y})$ (above, right). Scale-free connection distributions are typified by a minority of cells that host the majority of connections (nodes), while maintaining streamlined information flow due to a short pathlength. Although robust in the face of random attack, they are prone to collapse following a targeted attack (below, left). By contrast, nonscale-free networks (e.g., random or lattice) may not efficiently propagate signals due to a long pathlength, and random attacks significantly reduce capacity (below, right)

Imaging and mapping beta cell connectedness

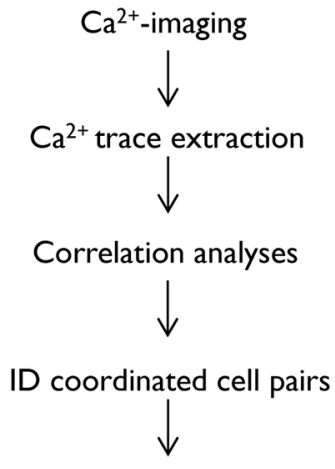

Map functional connectivity

\section{Scale-free network}

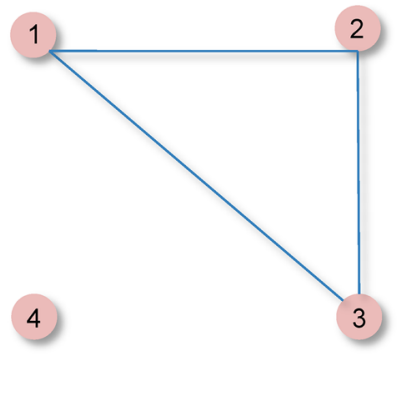

1

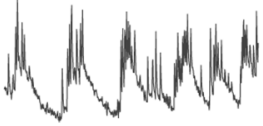

2

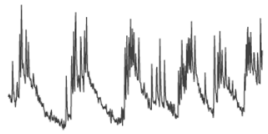

3
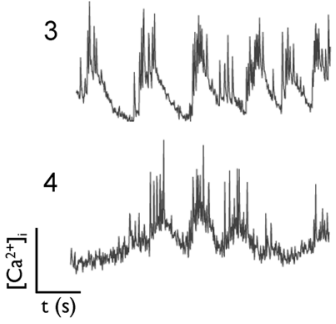

Random network

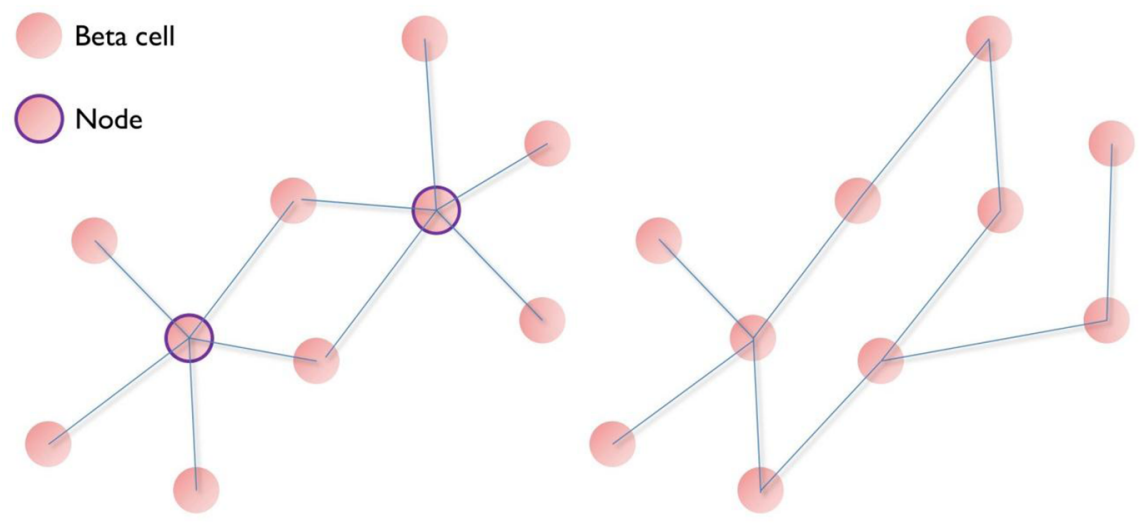

Pathlength $=$ short

Random attack functional loss $=10 \%$

Targeted attack function loss $=50 \%$
Pathlength $=$ long

Random attack functional loss $=20-40 \%$

Targeted attack function loss $=40 \%$ 
Fig. 2 Schematic showing single cell and populationlevel beta cell signaling. At the molecular level, glucose is transported into the beta cell before undergoing glycolysis to increase the ratio of free cytosolic ATP:ADP. This closes $\mathrm{K}_{\mathrm{ATP}}$ channels, leading to opening of VDCC, $\mathrm{Ca}^{2+}$ influx, and $\mathrm{Ca}^{2+}$-dependent exocytosis. At the population-level, beta cell dynamics are further dictated by signaling circuits involving paracrine, juxtacrine, autocrine, electrotonic (GJ), neural and ciliary communications

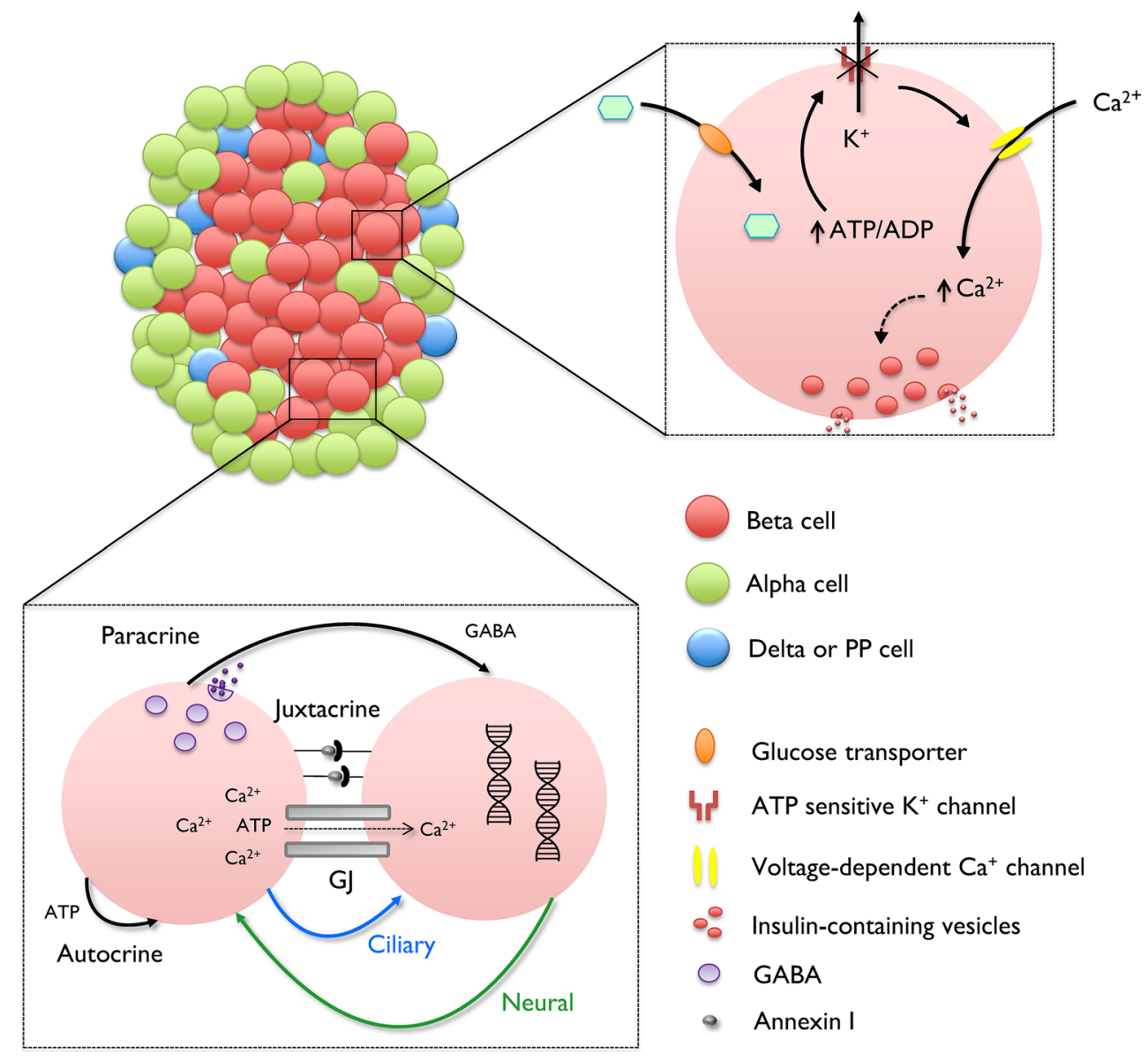

